\title{
Um panorama do Movimento Ocupe Estelita: design gráfico político e possíveis conexões
}

\author{
An overview of the Occupy Estelita Movement: political graphic \\ design and possible connections
}

\section{AZEVEDO, Paulo Fidelis}

Universidade Federal de Pernambuco - UFPE I fidelispaulao@gmail.com

SOUZA, Eduardo A.

Universidade Federal de Pernambuco - UFPE I souza.edrd@gmail.com

CADENA, Renata

Instituto Federal da Paraíba - IFPB I renata.cadena@ifpb.edu.br

\begin{abstract}
Resumo
A partir da reflexão de três participantes do Movimento Ocupe Estelita, este artigo tem o duplo objetivo de apresentar o movimento e de analisar, com foco no design gráfico, influências de outros movimentos políticos e semelhanças com eles. Para isso, descreverá o fluxo de trabalho dos designers engajados na produção de peças gráficas, que serão analisadas e categorizadas. Tal produção será discutida a partir de relações com 1) o movimento holandês Provos acerca de procedimentos e demandas, 2) a campanha chilena contra a continuidade de Pinochet no plebiscito de 1988 retratada no filme 'No'; e, 3) a série de protestos conhecida como Jornadas de Junho.
\end{abstract}

Palavras Chave: Design gráfico. Ativismo político. Design. Política.

\section{Abstract}

Based on the experience of three participants in the Occupy Estelita Movement, this paper aims both at presenting the movement and analyzing its influences and similarities in relation to other political movements - having Graphic Design as the primary focus. In order to do so, this study describes the workflow of designers engaged in the production of graphic pieces, which are analyzed and categorized. Such production is discussed in relation to 1) the Dutch movement Provos, 2) the Chilean campaign against Pinochet in 1988's referendum, and 3) the series of protests in Brazil known as the "Journeys of June".

Keywords: Graphic design. Political activism. Design. Politics. 


\section{INTRODUC̣ÃO}

O Movimento Ocupe Estelita (MOE) vem reunindo, desde sua formação em 2012, diversas pessoas contrárias à realização de um projeto imobiliário de grandes proporções no Cais José Estelita, região característica à beira do rio Capibaribe na cidade do Recife. Apesar de, nesse movimento, o termo 'Ocupe' originalmente fazer referência à ideia de 'utilizar o espaço', em 2014 diversos manifestantes de fato ocuparam o terreno com acampamentos, para evitar a demolição completa de galpões e o início das obras do conjunto de prédios, denominado Novo Recife. Nessa época, o acirramento do embate político foi acompanhado pelo florescimento de ações artísticas e, consequentemente, pelo aumento da demanda de ações comunicativas, a partir da qual emergiu um grupo de designers articulado pela internet que engajou-se no desenvolvimento da comunicação gráfica. Neste artigo, escrito por três participantes ativos do Movimento na época (dentre os quais, um ocupante fixo do Cais por cerca de 50 dias), apresentaremos o movimento, descreveremos o funcionamento do grupo de designers, e, por fim, classificaremos a produção gráfica realizada naquele período. Em um segundo momento, traçaremos paralelos do MOE com manifestações semelhantes em interesses, em forma de atuação ou em sua relação com a produção gráfica enquanto veículo de ideias. São eles: o holandês Provos, de 1965 e 1967; o caso do filme 'No', que retrata a campanha publicitária para impedir a continuação de Pinochet, no Chile de 1987; e as Jornadas de Junho, manifestações ocorridas em diversas cidades do Brasil em 2013, um ano antes do Ocupe Estelita.

\section{RECIFE INTEIRO É UM GRANDE CAIS JOSÉ ESTELITA - BREVE PANORAMA DA OCUPAC̣ÃO}

A lógica do lucro fundamenta o desenho das grandes cidades do país porque é resultado de projetos urbanísticos segregadores realizados pelas empreiteiras, as grandes financiadoras de campanhas políticas no país (REQUENA, 2014). O Estado ausente em sua função de regulador e redistribuidor de investimentos, pelo contrário, torna-se ator na viabilização desses projetos de concentração e exclusão: a especulação torna-se, então, um dos principais pilares da produção imobiliária privada (ROLNIK, 2003). O Recife é uma das somas dessa equação, em que certos espaços públicos são seletivamente negados à população; abandonados, produzem apenas insegurança.

No caso do Cais, os eventos começam em 2008, quando os 100 mil metros quadrados do terreno - o equivalente a dez campos de futebol - foram leiloados pela União de forma irregular. Nessa ocasião, a inexistência de uma série de estudos de organizações responsáveis foi desprezada, entre os quais destacam-se o estudo de impacto de vizinhança (EIV) e impacto ambiental 
(EIA). Similarmente, o projeto Novo Recife não possuía autorização de órgãos como IPHAN, DNIT, ANTT e Fundarpe, bem como inexistência de plano urbanístico para área ou a aprovação no Conselho de Desenvolvimento Urbano (CDU)

Apesar desse cenário de irregularidades, o Consórcio Novo Recife começou a demolição do Cais José Estelita, na zona central do Recife, na noite de 21 de maio de 2014. Para evitar a consumação da ilegalidade, o Movimento Ocupe Estelita, formado em 2012, iniciou a ocupação permanente do Cais. Foram quase trinta dias até uma reintegração de posse violenta, no dia 17 de junho de 2014 - simbolicamente realizada durante um jogo da seleção brasileira de futebol pela Copa do Mundo. Em seguida, os manifestantes ainda se mantiveram acampados por cerca de um mês do lado de fora do terreno, embaixo do viaduto Capitão Temudo, além de ocuparem também a prefeitura, exigindo negociação e alterações nas diretrizes do projeto.

Durante o tempo da ocupação, a cidade do Recife viveu momentos de debate intenso, em que parcela da população se uniu ao MOE contra a arbitrariedade com que a cidade estava sendo modelada. Essa reivindicação se relacionou a outras pautas urbanísticas, como o acesso popular à moradia adequada e o direito de usufruir do centro da cidade. As reivindicações do Estelita tiveram repercussão internacional, pautando veículos internacionais como o catarense Al Jazeera e o inglês The Guardian e atraindo acadêmicos como geógrafo britânico David Harvey, que visitou a ocupação e realizou uma palestra. Assim, o movimento tornou-se símbolo de resistência, propondo debates cruciais sobre o crescimento das zonas urbanas. Ao mesmo tempo, ao lado dos galpões demolidos, foram realizados eventos culturais, aulas públicas e apresentações de artistas brasileiros, alguns reunindo até dez mil pessoas ao longo do dia. O lugar se manteve movimentado e ativo, com uma estrutura sustentável de barracas, cozinha, banheiros artesanais e composteiras de lixo orgânico.

Apesar de o projeto Novo Recife não ter sido extinto até a publicação deste artigo, o MOE foi notadamente frutífero. Após a ocupação de 2014, as incongruências do projeto expostas à sociedade e, com a pressão política, os órgãos competentes entraram em atuação. Por exemplo, o leilão foi investigado pela Polícia Federal e chegou a ser anulado em 2015, mas foi declarado como legal novamente em recurso de 2017. Além disso, outros órgãos solicitaram laudos e ajustes para diminuir o potencial impacto do projeto, como a realização do documentário Recife, cidade roubada, textos de especialistas envolvidos no grupo 'Direitos Urbanos | Recife' também reúnem as informações necessárias (CÂMARA, 2012). Documentário Recife, cidade roubada. Direção: Ernesto de Carvalho, Leon Sampaio, Luís H. Leal, Marcelo Pedroso e Pedro Severien. Recife, 2014. Disponível em: youtube.com/watch?v=dJY1XE2S9Pk 
de pesquisas do serviço de arqueologia. Por sua vez, o Movimento, apesar de ter arrefecido as atividades desde a ocupação, continua com atenção sobre o local, realizando eventos ocasionais para que todo o debate suscitado não seja esquecido.

\section{DESIGN GRÁFICO POLÍTICO}

\subsection{Fluxo de Trabalho: o Funcionamento do Grupo de Designers por trás da Comunicação Digital do Movimento Ocupe Estelita}

Caracterizado pela horizontalidade, o MOE não contava com líderes expressos ou organograma fixo de funcionamento. Esse perfil perpassava desde a articulação política das ações até a organização dos grupos de trabalho que se formaram para executar atividades específicas. Em geral, esses grupos eram braços do Movimento que buscavam reunir profissionais de alguma área específica para dedicar tempo produtivo e expertise para a manutenção do MOE. Ou seja, aos poucos, e principalmente por meio das mídias digitais, - Movimento ganhava robustez com a adesão de dezenas de pessoas atuando diretamente na divulgação e na realização das diversas atividades que o caracterizaram. Entre os grupos, destacamos aqueles encarregados da comunicação e do design, os quais eram formados por jornalistas, publicitários, designers, ilustradores, artistas, professores e estudantes universitários que se articularam aos colegas de profissão que já estavam envolvidos no Ocupe Estelita antes da ocupação de maio de 2014.

A urgência e a intensificação desse trabalho estão relacionadas à ameaça de derrubada total dos galpões e a consequente ocupação do terreno no Cais José Estelita. A partir desse momento, as demandas latentes de publicização do debate sobre o projeto Novo Recife se intensificaram, pois associado ao interesse de estimular a participação da sociedade civil no futuro do Cais surgiram necessidades intrínsecas ao acirramento desse debate. $\mathrm{Ou}$ seja, a ocupação efetiva do espaço demandou uma comunicação direta com parcelas maiores da sociedade, com intuito de:

- defender os motivos da própria ocupação e das pessoas envolvidas;

- atualizar a sociedade sobre embates judiciais, políticos e policiais realizados mediante a ocupação do terreno - com um posicionamento autônomo, frente a uma mídia local que não simpatizava com o Movimento;

- divulgar dos eventos, de frequência quase diária, trazendo pessoas para conhecer a ocupação e as solicitações do MOE.

A intensificação das atividades e o ingresso de diversas pessoas interessadas em ajudar exigiu um esforço de organização das forças produtivas.

E, na ausência de uma sede com os equipamentos e estrutura necessários para 
essa tarefa, a rede social Facebook fez as vezes de agência, de redação. A opção por esse site foi muito natural, uma vez que era principalmente por meio dele, com seu caráter participativo e multimídia, que as atualizações sobre o MOE eram propagadas. Assim, as atividades foram organizadas em grupos secretos ou fechados ${ }^{2}$ no Facebook. O grupo voltado aos designers foi o grupo de Facebook 'Direitos Urbanos | Design', criado em 23 de maio de 2014, apenas dois dias após a ocupação do terreno no Cais José Estelita. Em 3 de junho, já contava com mais de 101 membros, podendo de ter reunido ainda mais participantes.

De maneira geral, o grupo reunia pessoas dispostas a ilustrar e formatar conteúdos gerados pela equipe de comunicação, que decidia, juntamente à articulação política do movimento, quais mensagens deveriam ser veiculadas. Então, quando os comunicadores apresentavam o conteúdo e o objetivo de uma determinada peça gráfica no grupo de Design, algum designer se oferecia para formatar esse material, gerando imagens digitais prontas para compartilhamento nas redes sociais (Figura 1). Para a realização dessas peças gráficas os diversos recursos visuais necessários foram organizados em um site de armazenamento de arquivos, que também concentrava as peças prontas. Os recursos incluíam componentes da identidade visual do MOE (símbolo, cores, fontes) e as diversas imagens continuamente criadas por fotógrafos e ilustradores solidários ao movimento. A forma de proceder ficava visível para todos os participantes do grupo digital em um fluxograma (Figura 1), criado para acelerar, esclarecer e padronizar os processos.

Figura 1 - à esquerda, exemplo de peça gráfica divulgando atividade na ocupação e, à direita, fluxograma.
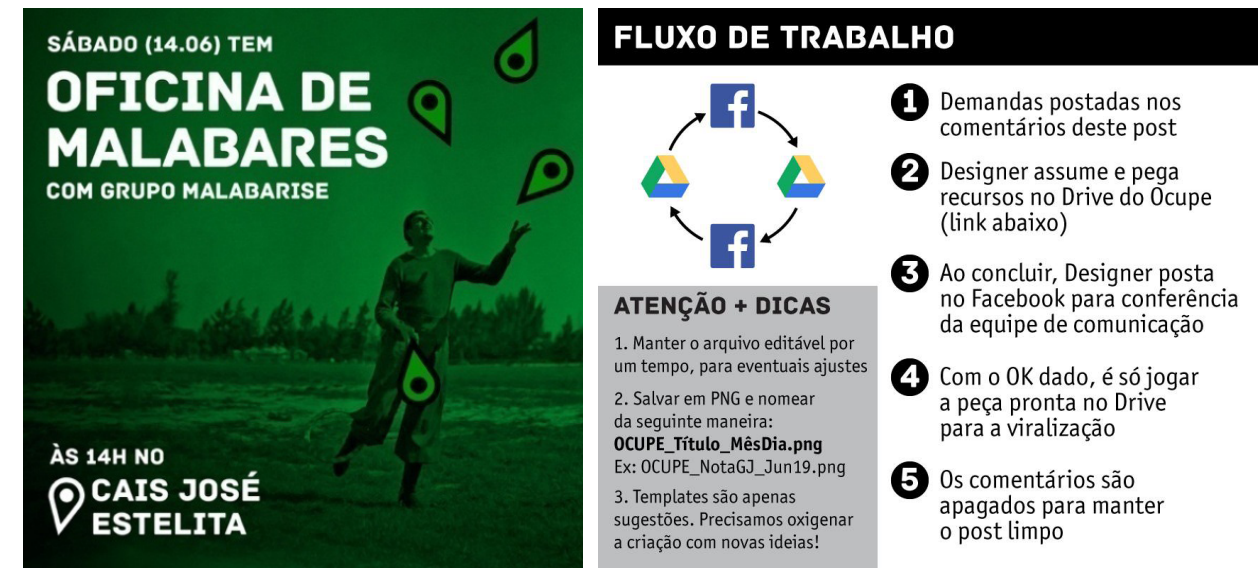

Fonte: Movimento Ocupe Estelita (2018).

Muitas vezes as atuações dos participantes eram mais fluidas do que consta nessa descrição, pois ideias e conteúdos de postagens surgiam de participantes de diversos outros grupos; inclusive de pessoas externas aos núcleos mais articulados aos integrantes e ocupantes do MOE. Essa autonomia motivou debates e contrassensos em situações pontuais, pois o conteúdo de

2 Um recurso que permite reunir privadamente uma série de usuários que podem compartilhar informações e arquivos digitais, e cujos participantes eram adicionados por convite. 
determinados materiais que carregavam o nome do movimento não coadunava com diretrizes, eventos e posicionamentos (mais ou menos) acordados entre seus membros. Foi o caso, por exemplo, de uma postagem contendo uma frase e imagem do Papa Francisco questionada por integrantes da ocupação devido ao confronto com o caráter laico do movimento.

No grupo de trabalho de Design, podemos elencar dois principais temas de debate entre os participantes: como ser mais efetivo na comunicação e o contínuo movimento de construção e consolidação de uma identidade visual para o movimento. Na busca de uma comunicação mais direta, o grupo discutia sobre o diálogo com a sociedade - sobretudo (mas não exclusivamente), por meio do espaço virtual - e os impedimentos que eram encontrados nesse processo, dentre os quais, destacamos:

- $\quad$ aspectos técnicos das mídias sociais, a exemplo do formato, tipo de arquivo e definição das imagens para ser mais acessível em vários dispositivos; - conhecimentos em design da informação para tornar o conteúdo mais efetivo, envolvendo o uso de textos menores e mais diretos, com cuidado na legibilidade e recorrendo à ênfase gráfica dos aspectos principais;

- $\quad$ estratégias de difusão das informações, considerando horários de maior acesso, maneiras de aumentar o alcance e visualização e táticas de facilitar o compartilhamento, como a inclusão de texto nas imagens.

O segundo tema, a construção de uma identidade visual, aconteceu de maneira peculiar. Essa prática é sobretudo corporativa, com fins comerciais e de caráter centralizado (WHEELER, 2008). Na contramão dessa abordagem, a construção da visualidade e gestão da imagem do Movimento foi e ainda vem sendo construída de maneira emergente e colaborativa, a partir do trabalho de pessoas que propõem soluções gráficas diversas, levando em consideração a visualidade pré-existente de algumas peças. Dessa maneira, não há um único símbolo, cor ou fonte, mas, diante dos mais de cinco anos de existência do movimento, sucederam-se estilos que marcaram determinadas épocas e que coexistem entre si.

Figura 2 - À esquerda, panfleto digital para a primeira edição do Ocupe Estelita, em 2012 e, à direita, panfleto para o evento comemorativo dos 5 anos do movimento.

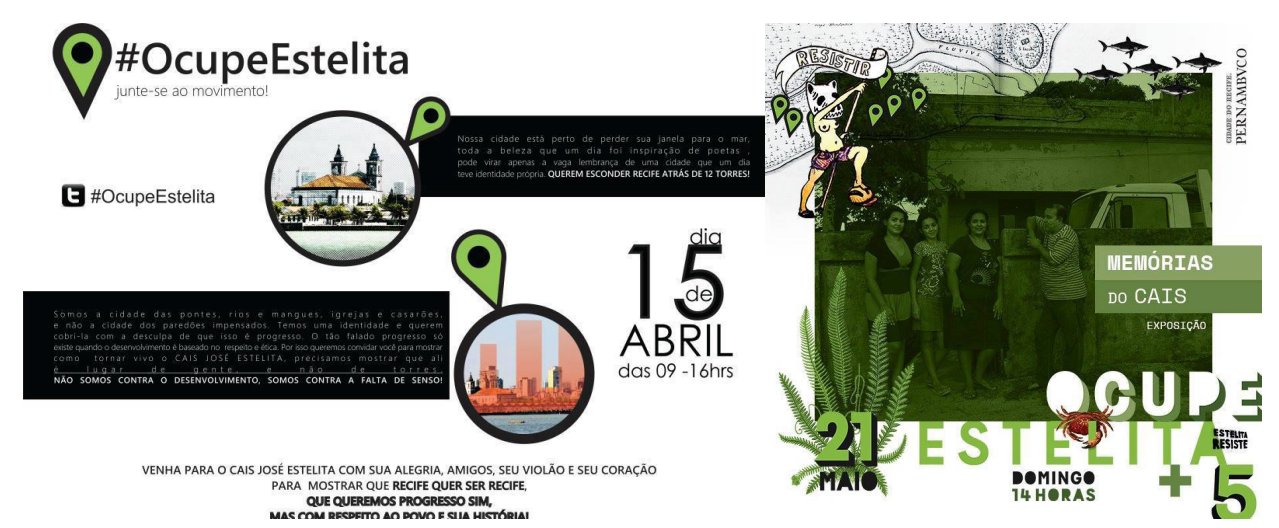

Fonte: Direitos Urbanos (2018) e Movimento Ocupe Estelita (2018). 
Durante o período da ocupação e em que o grupo de Design atuou de forma mais intensa, as diretrizes gráficas mais ou menos acordadas (fontes, padrão cromático, modelo de imagem, símbolo do movimento) facilitavam o trabalho dos participantes do grupo, que não precisavam alterar o layout significativamente se não tivessem disponibilidade para tal. Assim, a identidade visual do MOE não surgiu enquanto uma ação política centralizada que visava controlar os discursos visuais, mas foi um resultado da própria dinâmica produtiva das peças gráficas.

Assim, a existência de uma identidade visual trouxe benefícios para - MOE devido à atribuição de características de marcas em geral - como a expressão de conceitos, a fácil associação, e certa institucionalização e construção de credibilidade (WHEELER, 2008). Todavia, ela também foi utilizada por grupos agindo de má-fé para confundir e furtar todo o 'patrimônio' construído pelo Movimento. Foi o que aconteceu quando a equipe de comunicação do Novo Recife utilizou a mesma cor e tipografia parecida à utilizada pelo $\mathrm{MOE}$ em postagens patrocinadas ${ }^{3}$ que defendiam a realização do empreendimento imobiliário.

Figura 3 - Nota de repúdio publicada em 3 de junho de 2014.

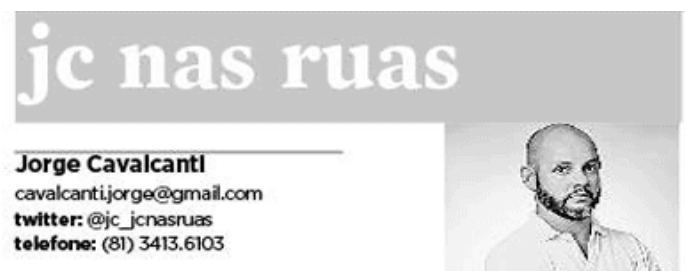

\section{A batalha da comunicação}

Contrários e favoráveis ao projeto do Consórcio Novo Recife são obrigados a concordar num ponto: a polêmica envolvendo o destino da área do Cais José Estelita cresceu. E deflagrou nos diretamente envolvidos a guerra da

comunicaçăo. Sobretudo nas redes sociais, de onde nasceu o principal foco de resistência ao projeto. Já dizia Chacrinha, o Velho Guerreiro, quem não se comunica...

O consórcio formado por quatro empresas, entre elas a

Moura Dubeux e Queiroz Galvăo, criou sábado uma conta no Twitter (@onovorecife), inclusive com as mesmas cor e

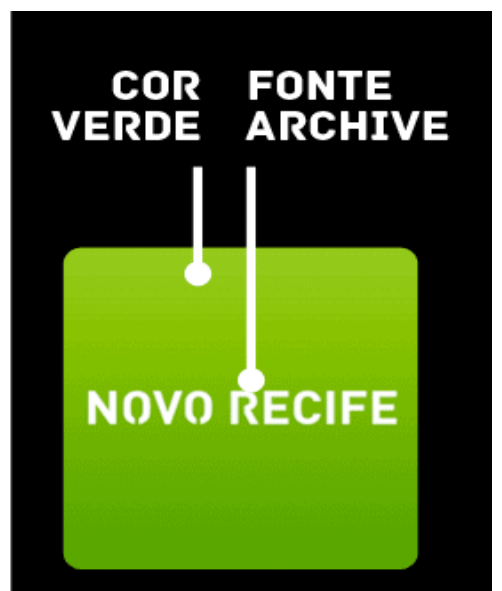

CILADA, BINO!

\section{OS 101 DESIGNERS QUE SE REVEZAM PARA CRIAR O MATERIAL DE DIVULGAÇÃO DO \#OCUPEESTELITA REPUDIAM A TÁTICA DESLEAL DA EQUIPE DE COMUNICAÇÃO DO CONSÓRCIO NOVO RECIFE DE COPIAR A IDENTIDADE VISUAL DAS PEÇAS COLETIVAMENTE CRIADAS PARA O OCUPE.}

Fonte: Movimento Ocupe Estelita (2018).

3

O Facebook oferece a possibilidade de se 'impulsionar' postagens a partir do pagamento de certas quantias, permitindo que elas alcancem um público maior - e customizado, de acordo com as preferências do público alvo - do que as postagens gratuitas. 


\subsection{Configurando o Discurso: uma Classificação para a Comunicação Segundo Demandas Políticas}

Além das demandas orgânicas, a ocupação desencadeou debates acerca da legitimidade das reivindicações e propostas do Movimento. As corporações de mídia, de um lado, retratavam a ação espontânea do MOE como um atraso e, de outro, o projeto Novo Recife como solução desenvolvimentista para o Cais, enviesando violentamente a opinião popular. Por conseguinte, o Movimento viu a necessidade contrapor essa narrativa, demonstrando as relações escusas entre poder público e empresas privadas que permitiram o início da derrubada dos armazéns e tornaram a ocupação necessária para a manutenção do devido processo legal. Portanto, nesta seção, buscamos apresentar um panorama da produção imagética do Movimento, sem a pretensão de exaurir as manifestações, nem mesmo de propor um canal "oficial".

Assim, poderíamos, grosso modo, classificar a produção do material gráfico digital em duas categorias: efêmera e campanhas. A produção de efêmera - conforme se refere em impressos, trata de "pequena documentação transiente do dia-a-dia" (UNIVERSITY OF READING, 2018.) - consistia na divulgação das atividades que ocorreriam nos eventos promovidos na ocupação do Cais. Já as campanhas possuíam planejamento de comunicação mais estruturado, ainda que a urgência dessa produção variasse muito: convocações para situações de risco poderiam ser discutidas e feitas muito rapidamente, ao passo que havia campanhas com planejamento mais desacelerado. Assim, nas campanhas, podemos subdividir ainda em duas abordagens que coexistiram com intensidades diferentes ao longo da ocupação. Em uma, que classificaremos como críticas, o intuito era ser o mais combativo quanto possível, buscando desconstruir o discurso das corporações de mídia e do Consórcio Novo Recife. Em outra, que chamaremos agregadoras, buscamos nos aproximar das pessoas que não tinham opinião consolidada sobre a ocupação ou sobre o projeto Novo Recife. Nesses casos, a comunicação apresentava um tom alegre e esperançoso, convocando a população a incluir-se no processo de decisão do futuro do Cais.

Figura 4 - Exemplo de material de efêmera (esq.), divulgando uma oficina na Escolinha Estelita que foi montada na ocupação; e de campanha, especificamente da comemoração de 50 dias (dir.).

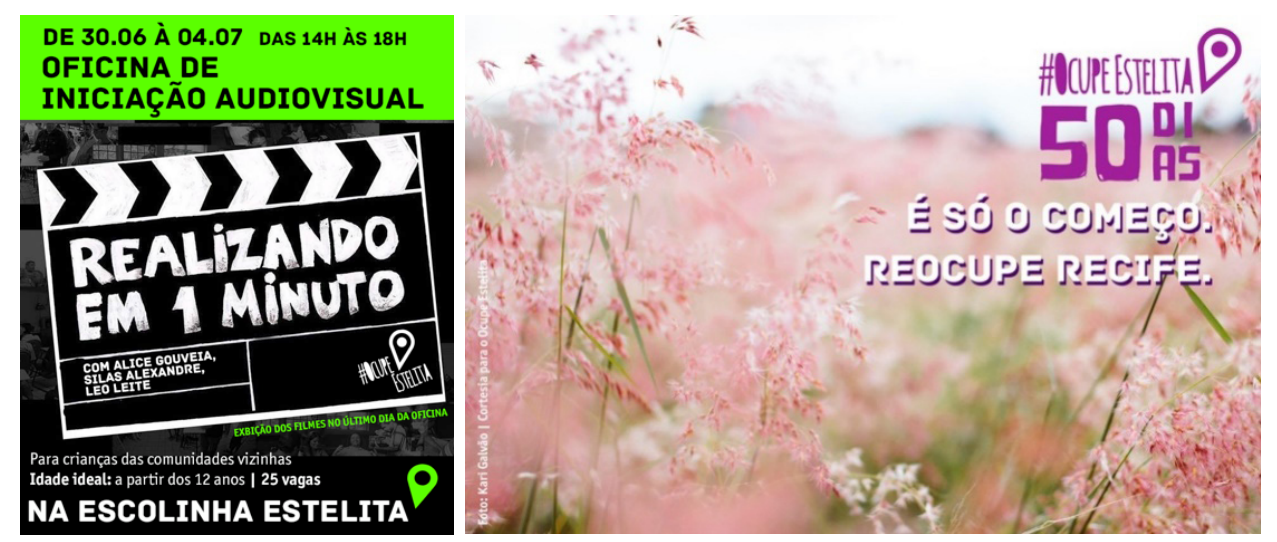

Fonte: Movimento Ocupe Estelita (2018). 
Figura 5 - Exemplo da subdivisão das campanhas. À esq., a categoria crítica, que visava a denunciar a violência da reintegração; à dir., agregadora, utilizando o material cultural que dialoga com a proposta do MOE.

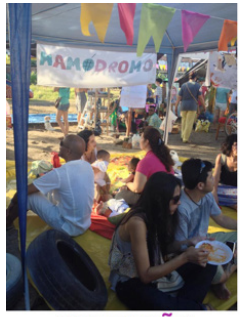

OCUPAÇÃO

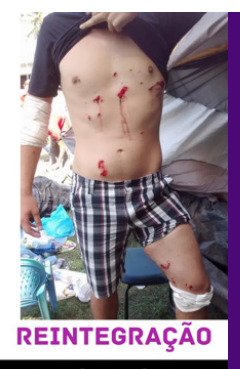

O QUE VOCÊ QUER PARA O RECIFE? A CIDADE É NOSSA. OCUPE-A.

Fonte: Movimento Ocupe Estelita (2018).

A estratégia das campanhas críticas consistia em reivindicar ações do poder público, denunciar abusos da repressão policial e demonstrar aspectos do processo que, no melhor dos casos, eram escusos - como a fraude no leilão do terreno, os financiamentos de campanha, as manobras de aprovação do projeto, entre outros. Com objetivo informativo, por exemplo, foram produzidos infográficos para explicitar as relações do poder público, desde 2012, com as empresas que capitaneavam o Consórcio Novo Recife (Figura 6, esq.). Mesmo nessa perspectiva, é possível encontrar manifestações jocosas, como o cartaz da Figura 6 (dir.). Por outro lado, em situações urgentes como na Reintegração de Posse do dia 17 de junho, a estratégia crítica consistia em apontar os abusos da Polícia Militar na ação.

Figura 6 - À esq., infográfico produzido para explicitar relações entre o poder público e empresas do consórcio. À dir., cartaz jocoso com a figura do então prefeito do Recife, feito para pressioná-lo a suspender a obra.
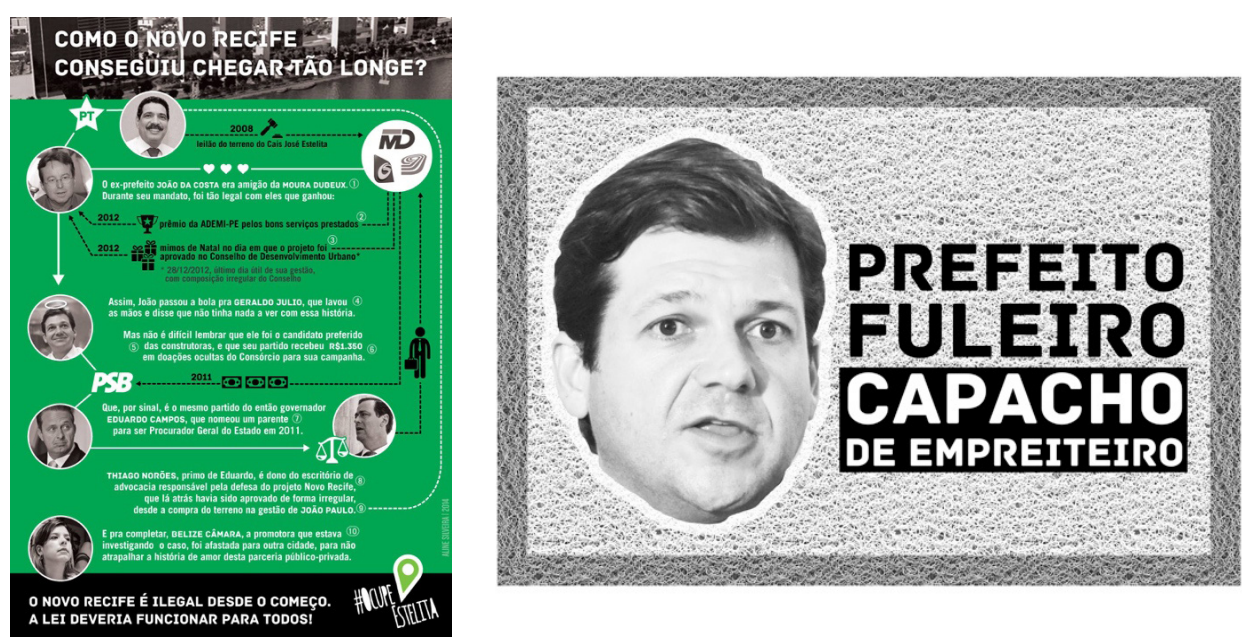

Fonte: Movimento Ocupe Estelita (2018).

Uma das direções mais importantes foi informar a população acerca da trajetória da venda do terreno no Cais e da proposta do Novo Recife para que o debate político fosse realizado de maneira justa. Por meio de estudos urbanísticos, argumentávamos que o projeto não correspondia aos anseios da população por uma cidade mais transitável e democrática. Problemas como 
trânsito - Recife foi apontado como a pior capital do Brasil ${ }^{4}$-, violência urbana - sobretudo no próprio Cais -, especulação imobiliária e gentrificação eram explicitados e discutidos pelo Movimento. O projeto do consórcio para o Cais era publicizado como um tratamento desenvolvimentista desses problemas urbanos, muito embora inúmeros especialistas apontassem que o próprio modelo de verticalização os causem estruturalmente. Por isso, foram feitos infográficos e peças informativas, até com simulações do skyline proposto pelo projeto e suas consequências para a circulação de ar pelo centro. Foram também produzidos impressos: livretos e zines para nos comunicar com parcelas da população que não acessavam o Facebook.

Figura 7 - Mockup do zine informativo produzido para distribuição, cujo texto foi tratado para a produção de infográficos mais acessíveis. Seguindo o tom agregador, o Cais José Estelita mostra-se como uma esperança.

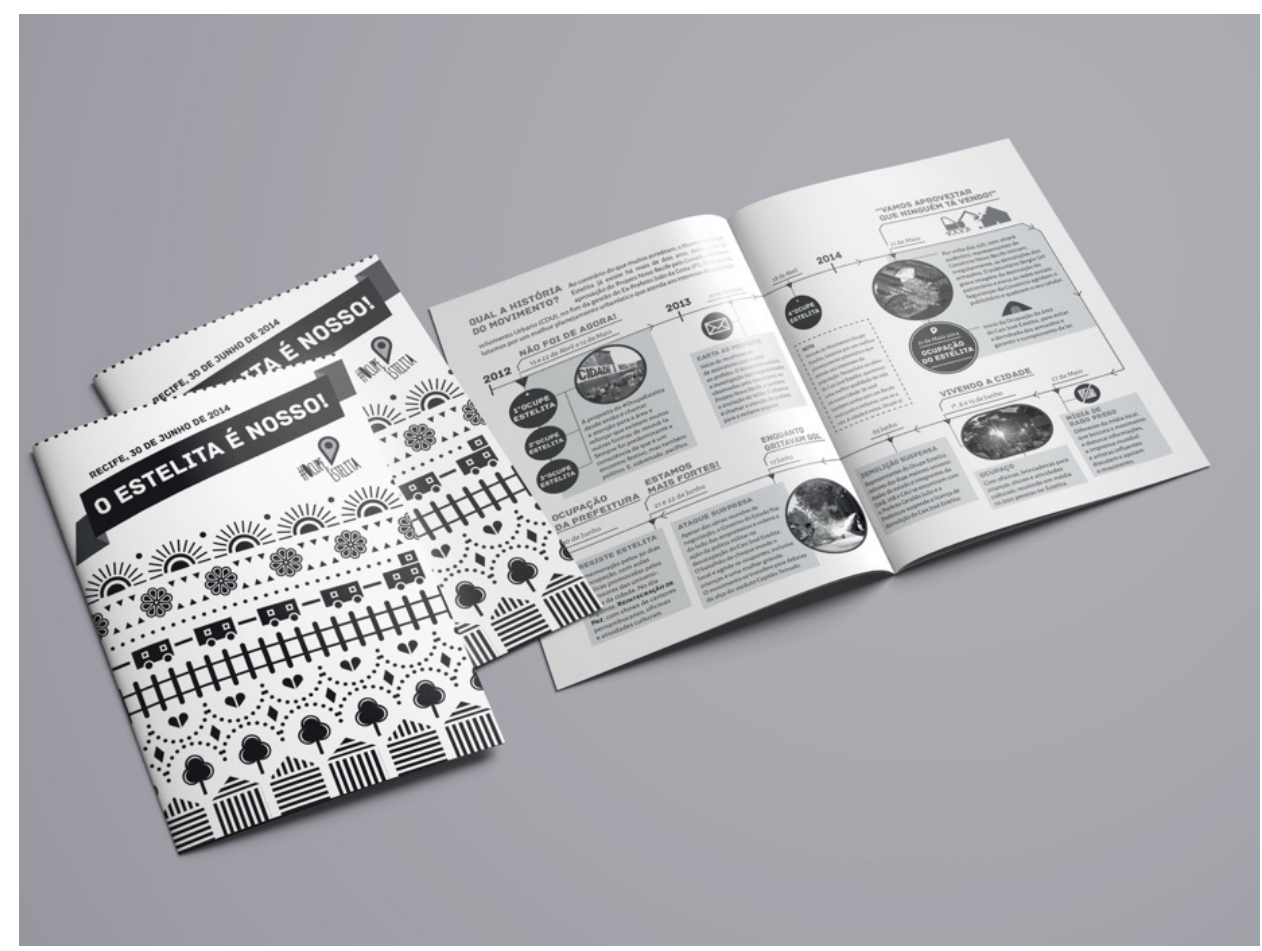

Fonte: Realizado pelos autores.

Todavia, é característica da abordagem crítica ter curta duração tanto em sua viabilidade material, nos casos informativos, quanto em seus efeitos, nos casos de urgência. Na prática, era fácil identificar que enquadrar o Cais como um problema a ser discutido trazia consigo um punhado de significados políticos e sociais que tendiam a afastar a população, fazendo com que aceitassem a opção mais imediata: se o consórcio tem alguma iniciativa, que seja feita.

A estratégia informativa tornou-se inviável porque a quantidade de pesquisa necessária para desconstruir o discurso vigente era grande e, assim, 
incompatível com a rapidez com que surgiam as demandas orgânicas do levante. Além disso, essas informações, no melhor dos casos, não geravam engajamento o suficiente nas redes sociais e, no pior, sequer chegavam a setores da população fundamentais para a mobilização. Já nos casos urgentes, conforme Rancière (2009) aponta, há um paradoxo em denunciar por meio do choque estético. Para seguir o exemplo citado, a exibição das imagens dos abusos da Polícia Militar que deveriam causar indignação e, depois, engajamento, acabam facilitando o mecanismo da naturalização. Isso se dá porque o discurso das corporações de mídia parece mais legítimo, ao passo que a denúncia "sempre é uma questão de expor ao espectador aquilo que não sabe como ver e fazê-lo sentir-se envergonhado daquilo que não quer ver (...)" (RANCIÈRE, 2009, p.2930, tradução nossa).

Visto isto, a segunda abordagem, a agregadora, buscava alternativas para integrar partes da população que não estavam sendo contempladas pela crítica urbanística - um tanto técnica - por meio de um discurso mais leve e participativo. Esse caráter festivo e integrador permeia o Movimento desde seu início, uma vez que os primeiros eventos para chamar atenção para o descaso com o Cais foram de lazer nos finais de semana. Todavia, o acirramento causado pela demolição dos armazéns fez com que o caráter político combativo se sobressaísse, conforme discutimos na abordagem crítica. De qualquer maneira, é importante ressaltar que ambos coexistiram ao longo de toda ocupação, desenvolvidos por grupos autônomos, simpatizantes da causa.

Uma importante referência para o grupo de comunicação foi o caso do plebiscito chileno de 1988, que discutiremos adiante. A partir dessa perspectiva, as campanhas assumiram crescentemente esse tom convidativo, a fim de envolver as pessoas por meio de ações colaborativas, inspirações artísticas e históricas, promoção de festas, cursos, palestras, oficinas. A comunicação dos eventos sociais tomou uma perspectiva mais agregadora que possibilitasse vivenciar o Cais como um local democrático. Daí surgiram campanhas como "Reintegração de paz", "Existe amor em Recife" e, mais tarde, "Amor pelo Recife, pela história, pela paisagem, pelo Cais, pelas pessoas" e a adoção de cores quase que oníricas para a paisagem do Cais.

De uma outra perspectiva, a produção de piadas, montagens e paródias foi muito profusa, fundindo crítica política e comédia, assim alinhada a outras manifestações culturais, como a Troça Carnavalesca Empatando Tua Vista, um bloco político e carnavalesco engajado contra a verticalização da cidade. Essa característica, tradicional da política pernambucana, pode ser observada desde o fim do século XIX, em revistas como O Diabo a Quatro e mesmo O Carcundão, a primeira manifestação de humor gráfico brasileiro (CÂMARA, 2017). Embora grande parte dessa produção fosse autônoma - inclusive, divulgada em outra página - e não integrasse a comunicação do $\mathrm{MOE}$, fazem parte da iconografia do evento político. 


\section{RELAC̣õES POLÍTICAS E TEÓRICAS DO MOE}

O Movimento Ocupe Estelita (2018) surge no afã do movimento anticapitalista e de contestação da desigualdade social surgida nos Estados Unidos Occupy Wall Street que, criado em 2011, contava com pessoas se revezando para fazer uma ocupação constante em Wall Street, principal centro das transações financeiras do país. Por compartilhar com esses ideais, o MOE toma de empréstimo o nome e, em 2014, o modus operandi do seu similar americano. Entre as várias insurgências e revoltas contra o establishment na história, selecionamos, em um zoom espaço-temporal, três momentos que serviram indireta e diretamente como influência para o movimento recifense:

- Os Provos, na Holanda da década de 60 é um marco no uso da arte, criatividade e irreverência para questionar a noção capitalista de cidade;

- $\quad$ o plebiscito no Chile do fim dos anos 80 retratado ainda que de maneira romantizada no filme 'No' contou com uma experimentação na linguagem da propaganda política para solapar a ditatura de Pinochet; e, por fim,

- $\quad$ os protestos urbanos acontecidos em 2013 em várias partes do Brasil, organizados de maneira descentralizada nas redes e explorando as novas tecnologias para representar e compartilhar seus ideais.

\subsection{Os Provos: a Produção Gráfica como Propulsora de Movimentos Contraculturais}

A revolta Provo 5 foi o primeiro episódio em que jovens, como grupo social independente, tentaram de alguma forma influenciar o território da política por meio de seus atos absolutamente originais, sem propor ideologias, mas um novo e generoso estilo de vida antiautoritário e ecológico (GUARNACCIA, 2001). O Provo produziu uma deflagração de consciência política que possibilitou uma visão de outras opções de vida. As ações dessa singular operação - que tinha Robert Jasper Grootveld como principal representante - aconteceram e se esgotaram entre julho de 1965 e maio de 1967 e ecoaram para além da Europa, inspirando uma quantidade enorme de imitadores.

Os membros do Provo questionavam a visão de cidade da época e o seu contexto urbano, sendo de grande importância para as discussões de vários outros movimentos no porvir, dentre os quais incluímos o Ocupe Estelita. Embora não tenha sido uma referência explícita ou pensada, as relações entre eles são

5 Matteo Guarnaccia resiste em usar o termo 'movimento' para nomear os Provos, utilizando-se poucas vezes do termo em seu livro, alguns momentos tratando-os nominalmente para evitar a classificação. Embora os Provos tenham sido nominados a partir de 1965, seus atos são anteriores a esse período. 
significativas. Os Provos, apesar de propor uma sociedade radicalmente diferente, se empenharam em permanecer "dentro" dela para provocar um curto-circuito por meio da arte - em especial, de happenings ${ }^{6}$. Era um grupo visionário, mas conscientes do fato de que nenhuma verdadeira revolução poderia se dar sem "evolução e sem alegria", utilizando-se da imaginação contra o poder, única arma à disposição.

Guarnaccia (2001) aponta que é com eles que subcultura torna-se contracultura, com uma guerrilha exemplar que propõe uma doce ideia de gestão da vida cotidiana. Todavia, ele pergunta: "como um grupo de visionários, composto por artistas de vanguarda, magos, vândalos, ex-situacionistas, estudantes desocupados, anarquistas, gente à toa e piromaníacos pôde ter êxito?" (GUARNACCIA, 2001, p. 14). O movimento se utilizou de recursos que beiravam o imprevisível, através de happenings, ludicidade e arte, além de um vasto material gráfico (Figura 7) como formas de protesto e resistência a uma sociedade que se recusava a ouvir os anseios de sua população. Jogos, brincadeiras e "vagabundagens" eram artifícios que instilaram nas mentes da juventude um desejo desmedido de anticonformismo, constituindo uma relação direta com o que parte conformista da opinião pública dizia a respeito dos que ocupavam o Cais Estelita.

A primeira iniciativa Provo são os folhetos assinados Provokatie (provocação, em holandês) que, de início, não encontram grande sucesso entre o público. Então, o movimento buscou espalhar sua ideologia de forma lúdica. Se, conforme Huizinga (1999, p.) "o jogo enfeita a vida, completa-a, e, como tal, é indispensável", o Provo ampliou a vida em sociedade. Uma das estratégias era esconder os panfletos dentro das páginas dos jornais, particularmente o diário sensacionalista de direita, o De Telegraaf, que inicia uma feroz e sistemática campanha de imprensa contra os Provos, que afinal aumentou a sua popularização. Muitos cidadãos de Amsterdã se identificaram com as ideias do movimento, acarretando maior participação em seus sabás noturnos e happenings que cada vez mais eram atacados pela polícia da cidade. Ainda assim, o movimento encontrava estratégias de contornar a censura imposta pelo governo.

Os Provos conseguiram patrocínios para as suas publicações, expandindo sua produção gráfica: a princípio, jornais e revistas mimeografados alcançavam cerca de 500 cópias, mas, com seu crescimento e investimento de outros setores da sociedade que os apoiavam, chegaram a imprimir milhares de cópias de uma mesma edição (GUARNACCIA, 2001). Essa mesma produção gráfica teve a coragem de contrariar os dispositivos de poder, escancarando os desmandos da burguesia de forma lúdica. Similarmente ao que ocorreu durante 
Figura 7 - Esq., 10 publicações, impressão offset em tamanho A5, A4 e A3, aproximadamente 16 a 20 páginas por publicação. Dir., publicação 11, impressão offset, 40 páginas. Abaixo, poster/Panfleto, 12 de julho de 1965, unilateral, mimeografado.
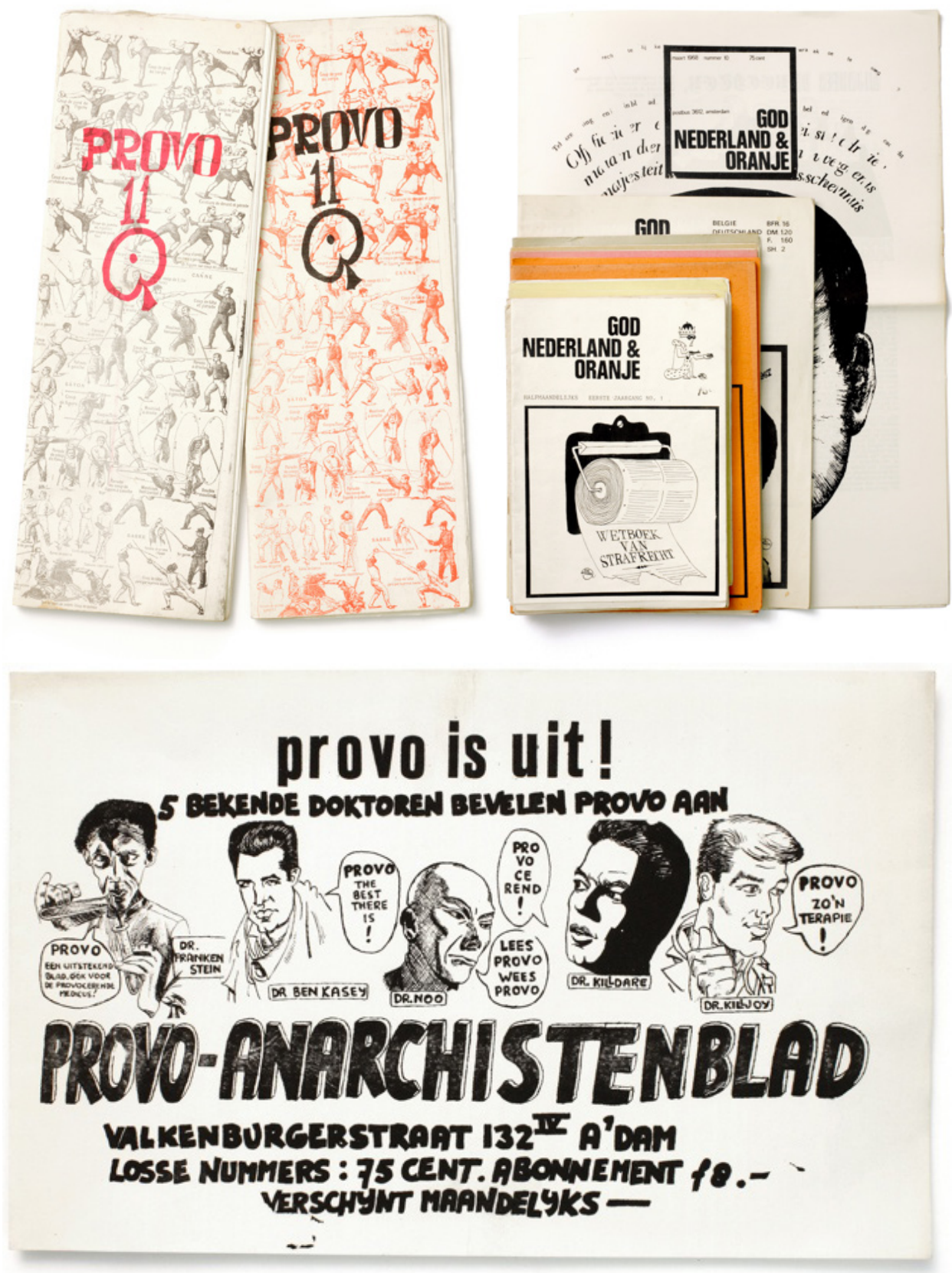

Fonte: (TWO..., 2017).

a ocupação do Estelita, a produção gráfica do Provo possibilitou propulsão e disseminação de seus ideais a diversas camadas da sociedade, buscando incorporar ainda mais pessoas ao movimento e questionar os usos do espaço urbano.

\subsection{No}

Como referência para a comunicação das campanhas do Movimento, surgiu o filme No (2012), de Pablo Larraín, baseado no romance El Plebiscito, de Antonio Skármeta. O enredo da narrativa se dá no fim da ditadura do General 
Augusto Pinochet, em 1988, quando é realizado um plebiscito nacional para que a população decidisse se ele deveria ficar no poder por mais oito anos - nesse caso, responderiam Sim - ou se deveria haver eleição no ano seguinte - nesse caso, Não. No filme, a campanha do Não, graças ao publicitário interpretado por Gael García Bernal, consegue reverter o cenário altamente desfavorável. Contra a máquina pública de propaganda e censura do governo militar deveriam usar uma abordagem contraintuitiva: em vez de denunciar as mortes e abusos dos militares, eles deveriam apresentar as possibilidades esperançosas de futuro por meio de um discurso leve e alegre.

Evidentemente, por se tratar de uma narrativa cinematográfica, houve omissão do contexto que antecedeu a realização do plebiscito, propiciando a consolidação da transição democrática, como o Acuerdo Nacional de 1985 e, no início de 88, a criação do Concertación de los Partidos por el NO, uma aliança de quinze partidos de oposição ao regime de Pinochet (SANTOS, 2014). Além disso, foram feitas adaptações. Por exemplo, resistência do grupo político ao conceito central da alegria foi exagerada, o que gerou crítica de personagens históricos representados ali. Genaro Arriagada - secretário executivo do Concertación, que organizou a campanha - afirmou que isso pôs a ideia de políticos ideologizados e ultrapassados de um lado e publicitários inovadores de outro, mas houve pouca resistência desde a primeira vez que discutiram um anúncio da Coca-Cola como referência (RIVAS, 2012). Apesar de certas liberdades, Eugenio García - em quem se baseou o protagonista interpretado por García Bernal - afirma que os principais marcos do processo criativo, da produção da campanha estão bem expressados (LLAUDÉS PENADÉS, 2013).

A campanha do No enfatizou a pluralidade partidária, o desejo pelo regime democrático e um caráter pedagógico importante para levar pessoas à votação, uma vez que a população não havia se envolvido dessa forma nos últimos 15 anos (SANTOS, 2014). Apesar das divisões ideológicas entre os partidos, a campanha ressaltou seu objetivo comum, de modo que o elemento visual central da campanha foi o arco-íris: unidade, pluralidade e carregado de conotações de alegria. Seu slogan oficial foi "Chile, la alegria ya viene!" e contou com a intensa participação de artistas e comunicadores sociais, além de agregar ações anteriores de coletivos artísticos (DELGADO, 2013).

A comunicação do MOE adotou essa abordagem também pela aguda pluralidade da ocupação, pois o Movimento defende o direito à cidade enquanto espaço para vivenciar, não apenas para transitar. Conforme Rocha (2015) aponta, o Movimento foi uma convergência de diferentes grupos: "de gays, lésbicas, transexuais, adeptos da bicicleta, do vídeo militante, da alimentação vegetariana ou vegana, de defensores dos animais e da descriminalização da maconha, dos trabalhadores do comércio informal e da moradia popular...". Assim, a necessidade de compartilhar experiências foi o ponto de unidade diante de pautas e necessidades tão distintas. A ocupação foi a realização de uma vivência democrática e, por isso, o Cais assumiu o status de símbolo 
de alegria e esperança para o Recife. O slogan utilizado pelo Movimento por muito tempo - "Ocupe Estelita. Ocupe a cidade." - evidencia que tratava de questões estruturais da sociedade, do qual o Estelita é um caso extremamente representativo, mas longe de ser pontual.

Nesse sentido, temos a semelhança em relação ao aspecto pedagógico da comunicação. No caso do No, foi fundamental para explicar como ocorreria o processo eleitoral e para assegurar que o voto seria secreto e que haveria condições de transparência - garantias conquistadas pela oposição que contava, inclusive, com apoio internacional (SANTOS, 2014). Essa segurança foi dos principais fatores para a efetiva participação popular: Navia (2004) aponta que no fim de 1987, 3 milhões de chilenos estavam inscritos para votar; esse número aumentou para 7,4 milhões quando as inscrições foram encerradas 30 dias antes do plebiscito.

\subsection{As Jornadas de Junho}

Ainda que o Movimento Ocupe Estelita tenha se iniciado em 2012, um dos antecedentes mais imediatos do que se tornou o movimento em 2014 foram as chamadas Jornadas de Junho, acontecidas no ano anterior. Dá-se esse nome a uma série de protestos irrompidos na cidade de São Paulo em 6 de junho de 2013 e propagados por várias cidades do país. Se o início das manifestações foi devido ao aumento nas passagens de ônibus na capital paulista, se intensificando diante da brutal repressão policial, os ecos da indignação inicial foram se avolumando - e/ou diluindo - em uma série de insatisfações de caráter político e econômico. E se, a princípio, os protestos em São Paulo estavam ligados ao Movimento Passe Livre, ao se espalhar pelo Brasil se deram de forma descentralizada, sem lideranças definidas, e utilizando as redes digitais como suporte para a expressão da indignação e para a articulação política.

Para Ferreira (2015), a internet tem papel preponderante nessas manifestações, por agregar "uma multidão que interagia principalmente pelas redes digitais, sem causar qualquer desconforto ao Estado e à grande mídia, até decidir ocupar as ruas" (FERREIRA, 2015, p. 7). Em sua expansão, grandes protestos aconteceram no dia 20 em várias cidades do país e também no Recife, levando cerca de 50 mil pessoas em passeata no centro da cidade. À altura, o protesto já era aguardado pelas autoridades locais e tanto o preço das passagens de ônibus havia sido reduzido como a manifestação teve a garantia de acontecer com 'proteção' da própria Polícia Militar. Assim, apesar desse caráter mais múltiplo e disperso (em temática, nos participantes), os protestos acontecidos no ano anterior servem como experiência para o Ocupe Estelita em termos de suas táticas de organização por meio das redes. 
Uma dessas ações em comum foi a abundante produção gráfica e artística sobre e para os movimentos, tanto por profissionais como por cidadãos comuns. Silva e Veneroso (2016) destacam a produção de cartazes de quatro tipos nas jornadas de junho: os itinerantes, portados nas passeatas; os lambelambes, colados nas paredes; os profissionais, realizados por especialistas simpáticos ao movimento; e os digitais, voltados ao compartilhamento na internet (Figura 8). A iniciativa da gráfica Meli-Melo (2018), em São Paulo, de convocar pessoas a criar cartazes que seriam gratuitamente impressos e distribuídos teve uma grande adesão, em mais uma expressão do engajamento no movimento sendo demonstrado também pelo viés da criação visual.

Figura 8 - à esquerda, imagens publicadas na rede social Instagram vinculadas à tag \#nãoésópor20centavos, um dos slogans da jornada de junho e, à direita, imagem de alguns dos cartazes impressos pela gráfica Meli-Melo.
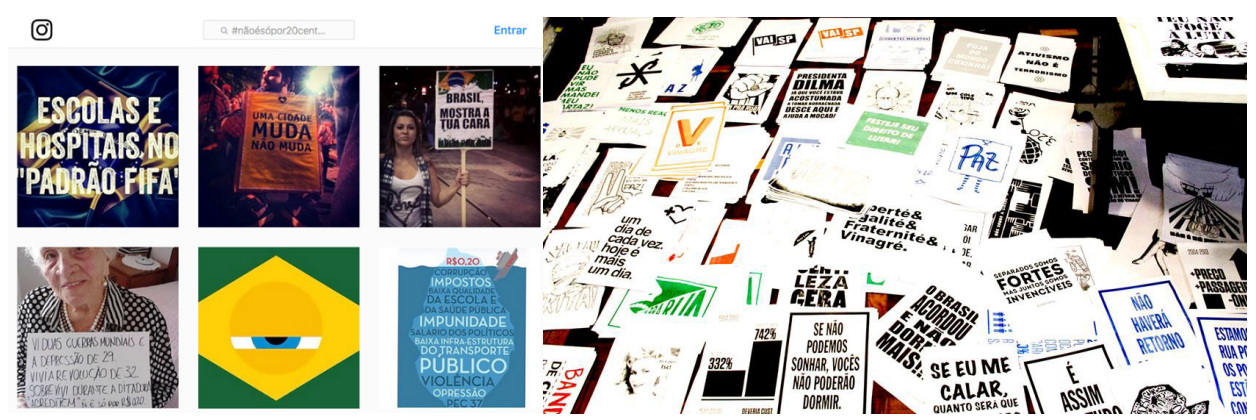

Fonte: Instagram (2018) e Meli-Melo (2018).

\section{CONSIDERAC̣ÕES FINAIS}

O Movimento Ocupe Estelita (2018) explorou estratégias de comunicação próprias do capitalismo para fazer um contraponto ao poder econômico, político e midiático do consórcio de empresas contra o qual estava lutando. Essa estratégia foi bem-sucedida pois impediu, até agora, a derrubada do Cais. Todavia, a mobilização digital perdeu força, uma vez que a lógica de mídia se estendeu para as redes sociais e, nos últimos quatro anos se tornou dominante. Paradoxalmente, enquanto havia a intensa vivência dos ocupantes no Cais por meio da imersão política e urbana na realidade da cidade, a perspectiva do grupo de comunicação virtual rapidamente se tornou de esgotamento nas imagens padronizadas e frases de efeito dos espaços digitais, uma vez que não conseguiam transmitir o debate político e a experiência da cidade. Ainda que múltiplo e controverso, o Movimento Ocupe Estelita (2018) foi uma expressão de fundamental importância para caracterizar novas possibilidades do agir político ensaiadas em manifestações políticas em todo Brasil. Dentre as inúmeras lições a serem discutidas pela experiência da ocupação, a vivência da cidade e as percepções distorcidas da realidade que são proporcionadas pelas redes sociais são as mais urgentes para o ano de 2018. Diante das instabilidades 
políticas do Brasil e do recente escândalo do uso de dados do Facebook pela empresa Cambridge Analytica, as ações políticas precisam achar outros meios de se manifestar, mais uma vez, reinventando-se.

\section{REFERÊNCIAS}

CÂMARA, Belize. Esclarecimentos sobre o Projeto Novo Recife. 2012. Disponível em: <direitosurbanos.wordpress.com/2012/12/29/ esclarecimentos-sobre-o-projeto-novo-recife-por-belize-camara>. Acesso em: 2 abr. 2018.

CÂMARA, Íkaro. Vera Cruz um artista gráfico ilustrador e litógrafo em Pernambuco: fins do século XIX e início do século XX. 2018. Dissertação (Mestrado em Design) - Universidade Federal do Pernambuco, Recife.

DELGADO, Teresa. No + Pinochet: documentación, publicidad y ficción en torno al plebiscito chileno de 1988. Berlin: J. K. Verlag, 2013.

DIREITOS URBANOS. Recife. Disponível em: <facebook.com/groups/ direitosurbanos>. Acesso em: 5 mar. 2018.

FERREIRA, Rubens da S. Jornadas de junho: uma leitura em quatro conceitos para a Ciência da Informação. Revista de Ciência da Informação e Documentação, Ribeirão Preto, v. 6, n. 2, p. 5-19, 2015.

GUARNACCIA, Matteo. Provos: Amsterdam e o nascimento da contracultura. São Paulo: Conrad, 2001. (Coleção Baderna).

HUIZINGA, J. Homo ludens: o jogo como elemento da cultura. São Paulo: Perspectiva, 1999. 
INSTAGRAM. Não é só por 20 centavos. Disponível em: <instagram.com/ explore/tags/nãoésópor20centavos>. Acesso em: 7 mar. 2018.

LLAUDÉS PENADÉS, Joaquín. Entrevista a Eugenio García, inspirador del No a Pinochet. 2013. Disponível em: <http://www.rebelion.org/noticia. php?id=163261>. Acesso em: 16 mar. 2018.

MELI-MELO. Disponível em: <facebook.com/MeliMeloPress>. Acesso em: 7 mar. 2018.

MOVIMENTO OCUPE ESTELITA. Que lutas cabem no cais. Disponível em: <https://www.facebook.com/MovimentoOcupeEstelita/>. Acesso em: 5 mar. 2018.

NAVIA, Patricio. Participación electoral en Chile, 1988-2001. Revista de Ciencia Política, Santiago, CL, v. 24 n. 1, p. 81-103, 2004.

RANCIÈRE, Jacques. The emancipated spectator. London: Verso, 2009.

REQUENA, Guto. Recife faz história. Folha de São Paulo, São Paulo, 29 jun. 2014. Disponível em: <http://www1.folha.uol.com.br/colunas/ gutorequena/2014/06/1477399-recife-faz-historia.shtml>. Acesso em: 16 mar. 2018.

RIVAS, Sebastián. El "no" de arriagada. 2012. Disponível em: <http://www. quepasa.cl/articulo/politica/2012/08/19-9152-9-el-no-de-arriagada.shtml/> Acesso em: 16 mar. 2018.

ROCHA, Maria Eduarda da Mota. O Estelita é mais do que o Estelita. 2015. Disponível em: <https://brasil.elpais.com/brasil/2015/11/30/ opinion/1448840154_656256.html> Acesso em: 16 mar. 2018.

ROLNIK, R. Política urbana no Brasil. Esperança em meio ao caos? Revista da ANTP, São Paulo, 2003

SANTOS, Eric Assis dos. A transição à democracia no Chile: rupturas e continuidades do projeto ditatorial. 1980-1990. 2014. Dissertação (Mestrado em História) - Universidade Federal Fluminense, Niterói.

SILVA, Rubens Rangel; VENEROSO, Maria do Carmo de Freitas. Arte gráfica de protesto: reflexões acerca dos cartazes políticos das jornadas de junho. Blucher Design Proceedings, São Paulo, v. 2, n. 9, p. 607-617, 2016. 
TWO or three things i know about provo. 2017. Disponível em <2or3things. tumblr.com>. Acesso em: 12 mar. 2018.

UNIVERSITY OF READING. Typography \& Graphic Communication. Research centres. Disponível em: <reading.ac.uk/typography/research/typresearchcentres.aspx>. Acesso em: 16 mar. 2018.

WHEELER, Alina. Design de identidade da marca. Porto Alegre: Bookman, 2008 . 